\title{
Genetic-geographic correlation revealed across a broad European ecotypic sample of perennial ryegrass (Lolium perenne) using array-based SNP genotyping
}

\author{
T. Blackmore ${ }^{1} \cdot$ I. Thomas $^{1} \cdot$ R. McMahon ${ }^{1} \cdot$ W. Powell ${ }^{1} \cdot$ M Hegarty $^{1}$
}

Received: 4 July 2014 / Accepted: 5 June 2015 / Published online: 21 June 2015

(C) The Author(s) 2015. This article is published with open access at Springerlink.com

\begin{abstract}
Key message Publically available SNP array increases the marker density for genotyping of forage crop, Lolium perenne. Applied to 90 European ecotypes composed of 716 individuals identifies a significant geneticgeographic correlation.

Abstract Grassland ecosystems are ubiquitous across temperate and tropical regions, totalling $37 \%$ of the terrestrial land cover of the planet, and thus represent a global resource for understanding local adaptations to environment. However, genomic resources for grass species (outside cereals) are relatively poor. The advent
\end{abstract}

Data Accessibility: All NGS sequence data used in this manuscript are available via the NCBI/GenBank short read archive (SRA) in the case of raw Illumina reads and as a Transcriptome Shotgun Assembly project for assembled transcriptome contigs (see text for accessions). Sequence metadata are captured under NCBI/GenBank BioProject accession PRJNA284350. Infinium iSelect probe sequences are available via the dbSNP repository under the accession numbers cited in the text. Genotype data for each marker/individual will be made available in the Illumina GenomeStudio format (i.e. AA, $\mathrm{AB}, \mathrm{BB})$ as tab-delimited tables on request.

Communicated by H. J. van Eck.

Electronic supplementary material The online version of this article (doi:10.1007/s00122-015-2556-3) contains supplementary material, which is available to authorized users.

M Hegarty

ayh@aber.ac.uk

T. Blackmore

tib10@aber.ac.uk

1 Institute of Biological, Environmental and Rural Sciences, Aberystwyth University, Gogerddan, Aberystwyth, Ceredigion SY23 3EE, Wales, UK of next-generation DNA sequencing and high-density SNP genotyping platforms enables the development of dense marker assays for population genetics analyses and genome-wide association studies. A high-density SNP marker resource (Illumina Infinium assay) for perennial ryegrass (Lolium perenne) was created and validated in a broad ecotype collection of 716 individuals sampled from 90 sites across Europe. Genetic diversity within and between populations was assessed. A strong correlation of geographic origin to genetic structure was found using principal component analysis, with significant correlation to longitude and latitude $(P<0.001)$. The potential of this array as a resource for studies of germplasm diversity and identifying traits underpinning adaptive variation is highlighted.

\section{Introduction}

Grassland ecosystems account for approximately $40 \%$ of the terrestrial land mass of our planet and are of critical importance to carbon sequestration, the bio-geochemistry of soils and the maintenance of biodiversity (Tilman et al. 1996; Jones and Donnelly 2004). Perennial ryegrass (Lolium perenne L.) is a dominant species of temperate grassland ecosystems, covering a broad range of environmental conditions (day length, moisture, altitude, soil type and chemistry, etc.). Understanding the patterns and magnitude of genetic diversity in the allogamous forage grass species $L$. perenne is thus a useful first step towards identifying loci under selection for multiple ecological traits, and also serves as a gateway for gene discovery in other grasses, with which it shares considerable synteny (Jones et al. 2002). To date, genomic resources in Lolium have been relatively poor, but NGS is rapidly facilitating 
the development of high-density marker assays, such as the Illumina GoldenGate assay developed by Studer et al. (2012).

The genetic diversity in wild populations (ecotypes) has previously been studied in $L$. perenne (Balfourier et al. 1998, 2000; Bolaric et al. 2005a, b; Cresswell et al. 2001; McGrath et al. 2007; Skot et al. 2005; Yu et al. 2011). These have all used techniques, such as AFLP, RFLP and RAPD, whereby only a low marker density was assayed and/or a limited number of populations surveyed. QTLs have been discovered in ecotypic populations for commercially important traits, such as heading date (with its association to digestibility) and submergence resistance (Skot et al. 2005; Yu et al. 2011), demonstrating that these natural populations offer opportunities to discover new marker/trait associations.

Studies of natural populations are increasingly turning towards high-density, genome-wide approaches to understanding genetic diversity (Brumfield et al. 2003; Garvin et al. 2010). The reasons for this are threefold: firstly, because such approaches provide extra resolution over older marker technologies-enabling fine-scale changes in population structure and/or history to be uncovered (Luikart et al. 2003; Morin et al. 2009). Secondly, these technologies lend themselves readily to association genetics studies of complex adaptive traits (Syvänen 2001) and, finally, due to the relative ease with which these assays can be established (Vignal et al. 2002). The advent of next-generation DNA sequencing (NGS) has enabled researchers to rapidly access genome-wide information for their study organism, regardless of whether a full genome sequence exists (Kircher and Kelso 2010; Morozova and Marra 2008). This provides a rich resource which can be mined for genetic markers-thousands to millions of single nucleotide polymorphisms (SNPs) can be putatively identified in silico for a modest outlay in NGS coverage. With access to highdensity SNP genotyping technologies, these markers can be used to screen large populations at a genome-wide level in timeframes which would be impossible with other markers such as SSRs or AFLPs (Brumfield et al. 2003; Willing et al. 2010). The genomic abundance and amenability to cost-effective high-throughput genotyping have meant that SNPs are developing into the most widely used class of genetic marker in the analysis and dissection of inherited complex traits, particularly those that contribute to adaptive, ecological variation (Bergelson and Roux 2010).

SNPs can be utilised using different methods: direct sample sequencing with techniques such as restriction site associated DNA sequencing (RAD; Baird et al. 2008) or genotyping by sequencing (GBS; Elshire et al. 2011) or by SNP array platforms. Each technique has its advantages which are applicable depending on the experimental design and overall aim (Thomson 2014). With the falling costs of sequencing, barcoding samples for NGS sequencing allows an accessible method of SNP genotyping with no prior sequence knowledge or reference genome. However, the bioinformatic analysis has greater demands in terms of pipeline integration and in computing power and storage capacity for the generated data. Furthermore, the reduced representational libraries in the form of RAD tags and GBS are heavily dependent on imputation to fill missing data (Huang et al. 2009). In contrast, once the initial sequencing, probe selection and marker validation has resulted in the creation of an SNP array, array-based genotyping provides a reproducible technique across users and laboratories. Sequencing-based methods are also often prone to loss of shared loci across experiments, whilst array-based markers perform relatively consistently (though individual markers may be monomorphic or null in given populations). The resulting genotypes are thus easy to compare to previous data and experiments due to the same SNPs being typed. Unlike NGS techniques, the analysis of array platform data is possible with a desktop computer with minimal memory/ storage requirements.

We report here on the creation and validation of a publically available custom Illumina Infinium SNP genotyping microarray for $L$. perenne represented by 2185 validated SNP markers and its application to screening a large European ecotype population of over 700 individuals. We assess the population structure of this collection and note the strong correlation of genotype to geographic origin, which suggests the value of this array for studies of population genetics and adaptive trait variation in ryegrass.

\section{Materials and methods}

\section{Next-generation sequencing}

To identify putative SNP loci which could be used to construct an Infinium assay, we conducted Illumina RNAseq of five diverse genotypes of $L$. perenne which were contributed as clonal replicates (tillers) by the researchers referenced below. The five genotypes selected were: AberMagic (an IBERS synthetic forage variety, R. Hayes, pers. comm.); a Chromosome 3 substitution line with Festuca pratensis (King et al. 2002); a mother plant from the IBERS late heading recurrent breeding population (R. Hayes, pers. comm.); a "stay-green" amenity variety (Thorogood et al. 1993) and an early flowering ecotypic sample from France previously described in Skøt et al. (2007). These genotypes thus represent a selection of $L$. perenne from wild to highly selected "domesticated" lines. As we were not concerned with gene expression (only SNP detection), a single individual was grown for each genotype. Each individual was harvested at the young (3-4 weeks post-germination) stage 
and total RNA isolated from both total above and below ground biomass using Trizol extraction (Sigma Aldrich). The above/below ground extracts were pooled for each individual genotype at equimolar concentrations prior to Illumina RNAseq library construction, to provide as much coverage of the transcriptome at equivalent life history stages (flowering tissue was ignored as the genotypes used display significant variation). Aliquots of $2 \mu \mathrm{g}$ of total RNA per genotype were used to prepare libraries as per the Illumina mRNA-seq protocol (mRNA-Seq 8-sample Prep Kit (RS-100-0801). Each library was sequenced in a single lane of an Illumina GA-IIx platform at GenePool (University of Edinburgh) using paired-end $2 \times 56$ bp sequencing. Read count averaged 41 million reads per genotype (20.5 million pairs), with the lowest output being the amenity genotype with 13 million pairs and the highest AberMagic (50.5 million pairs). Raw FASTQ data for these libraries are available through the NCBI short read archive (http://www.ncbi. nlm.nih.gov/sra), accessions SRR2034619-SRR2034623.

\section{Sequence assembly and SNP detection}

Reads were imported into the Genomics Workbench version 4.5.1 package (CLC Bio Ltd.) and a reference transcriptome was assembled de novo using the reads from AberMagic, since it generated the highest read coverage. De novo assembly in Genomics Workbench uses the de Bruijn graph method with a k-mer value assigned based on the scale of data input (for $2.75 \mathrm{Gbp}$ as here, a k-mer of 23 is assigned). The maximum bubble size for conflict resolution within the graph was set at 50. Repeat regions within the graph were resolved using scaffolding based on paired-end sequences. Following initial contig assembly, reads were mapped back to contigs, requiring $50 \%$ match at $80 \%$ similarity across the read. Ambiguous read mappings (reads mapping to more than one contig) were discarded from the mapping. Insertion and deletion penalties were set at 3 and mismatch penalty at 2 . Contigs from the initial assembly were removed if no reads mapped. This step was included to resolve conflicts by generating a consensus based on the most common base for each position.

This assembly produced a total of 55,181 contigs which were used as the reference for read mapping of the five genotypes. This Transcriptome Shotgun Assembly project has been deposited at DDBJ/EMBL/GenBank under the accession GDAT00000000. The version described in this paper is the first version, GDAT01000000. BLASTx annotation of contigs (Altschul et al. 1990) was performed within the Genomics Workbench package using a local copy of the non-redundant (nr) protein database (downloaded circa August 2011). Individual mappings were produced for each genotype (as above, but employing $50 \%$ match at $95 \%$ identity across each read), which were then mined for the presence of SNPs. Non-specific read mappings (reads mapping to $>1$ contig) were ignored (to avoid identification of SNPs within multigene families), and a minimum quality score of 20 was requested surrounding the putative SNP (quality score for the SNP itself was requested as 30 or higher). To further increase stringency and avoid issues with sequence error, a minimum read coverage of 50 was requested for each SNP. Minor allele variant detection threshold was set at $25 \%$ for similar reasons. Despite the stringency of these criteria, a total of 53,149 putative SNPs (within 11,892 unique contigs) were identified across the five genotypes.

\section{Infinium assay design}

Despite the high number of putative SNPs identified, not all the putative SNPs identified were suitable for construction of Infinium probes: firstly, we needed to maximise the likelihood that markers would be informative across a broad range of material. Secondly, we needed to account for the possibility of misassembly during the de novo contig construction and remove sequences which might be present in high copy number. To address the first issue, we subselected markers which showed evidence of polymorphism in two or more of the accessions, reducing the possibility that a particular marker might not show polymorphism in wider L. perenne collections. For example, whilst we included the chromosome substitution line of King et al. (2002) because of its relevance to IBERS breeding programmes, the Festuca material might otherwise contribute a significantly higher number of polymorphisms (though in the event, this material showed a similar number of variants to AberMagic itself, with the natural $L$. perenne ecotype displaying the most polymorphism).

With regard to the possibility of misassembly in the contig data, we, therefore, excluded any contigs displaying evidence of frameshift (multiple hits to the same match) within their BLASTx result. Further filtering on BLAST identifier was then applied to remove likely organellar or retroelement sequences (as suggested by Illumina), which are likely to be present in high copy number or overrepresented in DNA extracts used for genotyping.

Finally, a minimum flanking sequence of $50 \mathrm{bp}$ is required around the SNP for Infinium probe design (60 bp preferred), which would exclude some SNPs positioned close to the ends of contigs. Although Infinium technology is more tolerant of the presence of other SNPs within the probe sequence, we decided to err on the side of caution and also eliminate any SNPs within $50 \mathrm{bp}$ of each other. Custom PERL scripts were designed to mine the contig FASTA file based on the SNP report tables produced by Genomics Workbench and isolate SNPs with sufficient flanking sequence which were $>50$ bp away from any other 
SNP. These filters reduced the number of possible SNPs to 4513 (spread across 2943 contigs). A custom PERL script was then employed to extract the flanking 50-60 bp around each marker and annotate the SNP itself with the format [allele1/allele2]. This provisional SNP probe set was uploaded to the Illumina Assay Design Tool (ADT) and the SNPs assessed for probe designability. SNPs with designability scores of 0.6 or higher were selected for inclusion in the final array design, producing an initial assay of 3775 putative SNPs in total. Subsequent validation steps (described below) reduced the final marker set to 2185 SNPs.

\section{Plant material}

A bi-parental mapping population (Hegarty et al. 2013), consisting of 193 progeny and two parents (AberMagic $\times$ Aurora), was selected to use as a basis of marker validation via allele heritability. In addition, six progeny and two parental replicates were included to assess genotyping error rate.

The ecotype collection used for array validation was formed from $L$. perenne seed collected at various sites across Europe (Table 1) and subsequently germinated. Accessions were selected from an existing seedbank kept at IBERS, Aberystwyth, in order to represent a range of geographical locations (latitude, longitude and altitudes) as well as environments and land management conditions. Plants from each accession were allowed to polycross to bulk seed for each location. Plants and seed were maintained at IBERS, Aberystwyth University. Leaf tissue was harvested from individual Lolium plants and DNA was extracted using QIAGEN 96 plant tissue extraction kit. A total of 716 individual $L$. perenne ecotypes from a range of locations and environments across Europe were used, with 8 individuals within each of 89 accessions and four individuals from one accession.

\section{Genotyping and assay validation}

Genotyping was performed as per the manufacturer's guidelines using the Illumina Infinium iSelect custom assay (Illumina, San Diego, CA, USA). There was a $91 \%$ assay conversion rate resulting in 3425 putative SNPS on the final array (2334 in unique contigs). The L. perenne ecotype population of 716 individual plants (in addition to five randomly selected replicates) was genotyped using the custom Infinium assay and the data used to produce a cluster file for allele calling. Clustering was initially performed using automated cluster assignment within Illumina's Genome Studio software. However, comparison of the clustering of the SNPs was inconsistent and manual reassignment of cluster position was required. This was independent of the original GenTrain score and, therefore, we were unable to manually reassign the cluster position to only SNPs with a GenTrain score below a certain threshold. Therefore, although laborious, all SNPs were visually inspected by one person for their original automated AA/ $\mathrm{AB} / \mathrm{BB}$ cluster positions and manually reassigned where appropriate. This also included the exclusion of SNPs with poor performance in this genetically diverse population. Markers were excluded where the average intensity ( $R$ mean) for each cluster was below 0.2 or cluster separation was less than 0.3. Markers were reviewed where cluster separation ranged between 0.3 and 0.45 (guidance from clustering algorithm metrics from Illumina). Markers were also excluded where there were missing data for more than $10 \%$ of 716 samples, leaving 2501 markers at this stage. The wide range of genotypes used at this stage will maximise the general utility of the selected probes for further studies, because any interference due to genetic polymorphism resulting from genetic distance between the sequenced plants and the tested individuals will lead to exclusion from the array at this stage.

Although the original 5 individuals that were sequenced for the identification of SNPs were genotyped on the array, the comparison of the RNA sequence data to the genomic DNA SNP array proved difficult due to lack of information on allelic expression bias. Therefore, to further validate the markers, the cluster positions of the 2501 markers on the ecotype samples were exported and applied to the biparental mapping population that had also been genotyped on the array. This enabled use of heritability of alleles within a segregating population to be employed as confirmation of marker behaviour. Of the 2501 markers, 43 markers had more than four parent-parent-child heritability errors and were subsequently excluded, leaving a total of 2458 markers for further analysis on the ecotype population.

Thus, following reassignment of cluster positions or exclusion of markers using all 716 samples 2458 loci were exported. 239 had a minor allele frequency less than $5 \%$ and were, therefore, excluded. Markers were also tested for observed heterozygosity (Ho) excess using GenePop (Raymond and Rousset 1995) in each of the 90 accessions. 34 markers with a probability less than 0.5 for Ho excess were also excluded to minimise genotyping errors. Following these exclusion parameters, a final validated set of 2185 SNP markers (spanning 1606 unique contigs) was available and used to assess the genetic diversity in the ecotype panel. Marker details have been uploaded to dbSNP (http://www.ncbi.nlm.nih.gov/SNP/) under accessions ss1751856902-ss1751859086 and are due for public release in Autumn 2015. Probe details are thus also provided in Supplementary Data Table 2. Marker names follow the convention "ContigX_Y" where $\mathrm{X}$ is the contig number as in the NCBI Transcriptome Shotgun Assembly 
Table 1 Geographic location of sample site for each accession

\begin{tabular}{|c|c|c|c|c|c|}
\hline ID & Accession & Country & Longitude $\left({ }^{\circ}\right)$ & Latitude $\left(^{\circ}\right)$ & $\begin{array}{l}\text { Altitude } \\
\text { (MASL) }\end{array}$ \\
\hline AT1 & Ba10985 & Austria & 14.07 & 48.28 & 310 \\
\hline BG1 & Ba12019 & Bulgaria & 24.78 & 42.85 & 525 \\
\hline BG2 & Ba12020 & Bulgaria & 24.78 & 42.85 & 600 \\
\hline BG3 & Ba12028 & Bulgaria & 26.18 & 42.90 & 490 \\
\hline BG4 & Ba12039 & Bulgaria & 23.35 & 42.62 & 760 \\
\hline BG5 & Ba12049 & Bulgaria & 22.48 & 42.22 & 1060 \\
\hline $\mathrm{CH} 1$ & $\mathrm{Ba} 10282$ & Switzerland & 7.68 & 47.37 & 1120 \\
\hline $\mathrm{CH} 2$ & Ba10284 & Switzerland & 8.85 & 47.44 & 720 \\
\hline $\mathrm{CH} 3$ & Ba10286 & Switzerland & 8.93 & 47.28 & 1200 \\
\hline $\mathrm{CH} 4$ & Ba10288 & Switzerland & 7.77 & 46.40 & 1840 \\
\hline $\mathrm{CH} 5$ & Ba9101 & Switzerland & 7.38 & 46.18 & 2030 \\
\hline CH6 & Ba9105 & Switzerland & 8.85 & 47.43 & 600 \\
\hline $\mathrm{CZ1}$ & Ba11862 & Czech_Republic & 17.85 & 49.45 & 380 \\
\hline CZ2 & Ba11865 & Czech_Republic & 18.10 & 49.48 & 500 \\
\hline $\mathrm{CZ3}$ & Ba11869 & Czech_Republic & 17.98 & 49.67 & 240 \\
\hline $\mathrm{CZ4}$ & Ba11878 & Czech_Republic & 18.03 & 49.47 & 280 \\
\hline Eng1 & Ba10015 & England & -1.26 & 51.75 & 57 \\
\hline Eng2 & Ba10292 & England & 0.76 & 50.96 & 0 \\
\hline Eng3 & Ba11141 & England & -0.14 & 52.84 & 0 \\
\hline Eng4 & Ba11143 & England & -0.67 & 52.77 & 120 \\
\hline Eng5 & Ba13209 & England & -2.87 & 51.02 & 30 \\
\hline Eng6 & $\mathrm{Ba} 13228$ & England & -2.33 & 54.77 & 550 \\
\hline Eng7 & $\mathrm{Ba} 13240$ & England & -2.82 & 51.30 & 230 \\
\hline Eng8 & Ba13241 & England & -2.77 & 51.28 & 100 \\
\hline Eng9 & Ba9960 & England & -2.81 & 51.23 & 0 \\
\hline ES1 & Ba13697 & Spain & -0.18 & 42.66 & 1734 \\
\hline ES2 & $\mathrm{Ba} 13698$ & Spain & -0.17 & 42.62 & 1245 \\
\hline ES3 & Ba13705 & Spain & -0.30 & 42.72 & 1092 \\
\hline ES4 & $\mathrm{Ba} 13706$ & Spain & -0.42 & 42.80 & 1760 \\
\hline ES5 & $\mathrm{Ba} 13724$ & Spain & -0.61 & 42.33 & 1075 \\
\hline ES6 & Ba13735 & Spain & -0.02 & 42.57 & 1299 \\
\hline ES7 & Ba13740 & Spain & -0.53 & 42.68 & 982 \\
\hline ES8 & $\mathrm{Ba} 13858$ & Spain & -5.85 & 43.20 & 857 \\
\hline ES9 & Ba13859 & Spain & -5.91 & 43.17 & 1535 \\
\hline ES10 & $\mathrm{Ba} 13860$ & Spain & -5.90 & 43.17 & 1373 \\
\hline ES11 & Ba13867 & Spain & -5.89 & 43.16 & 895 \\
\hline ES12 & $\mathrm{Ba} 13874$ & Spain & -7.01 & 43.35 & 877 \\
\hline ES13 & Ba13876 & Spain & -6.22 & 42.58 & 1194 \\
\hline ES14 & Ba13877 & Spain & -7.00 & 42.73 & 1229 \\
\hline ES15 & Ba13882 & Spain & -6.17 & 42.85 & 1253 \\
\hline ES16 & Ba13884 & Spain & -6.40 & 42.97 & 1379 \\
\hline ES17 & Ba13885 & Spain & -5.87 & 43.38 & 374 \\
\hline ES18 & Ba13892 & Spain & -5.61 & 43.18 & 851 \\
\hline FR1 & Ba9109 & France & 6.13 & 48.30 & 287 \\
\hline GR1 & Ba11900 & Greece & 20.78 & 39.55 & NA \\
\hline HU1 & Ba11311 & Hungary & 20.58 & 46.85 & NA \\
\hline IE1 & Ba10127 & Ireland & -8.75 & 53.29 & 100 \\
\hline IE2 & Ba10148 & Ireland & -8.29 & 51.79 & 50 \\
\hline IE3 & Ba10153 & Ireland & -9.68 & 51.41 & 2 \\
\hline IE4 & Ba10162 & Ireland & -9.44 & 51.68 & NA \\
\hline IE5 & Ba10170 & Ireland & -9.50 & 52.06 & 20 \\
\hline IE6 & Ba10178 & Ireland & -8.34 & 54.68 & 40 \\
\hline
\end{tabular}


Table 1 continued

\begin{tabular}{|c|c|c|c|c|c|}
\hline ID & Accession & Country & Longitude $\left({ }^{\circ}\right)$ & Latitude $\left(^{\circ}\right)$ & $\begin{array}{l}\text { Altitude } \\
\text { (MASL) }\end{array}$ \\
\hline IT1 & Ba13445 & Italy & 12.55 & 46.32 & 800 \\
\hline IT2 & Ba13448 & Italy & 13.50 & 45.85 & 100 \\
\hline IT3 & Ba13457 & Italy & 12.92 & 46.08 & 250 \\
\hline IT4 & Ba13458 & Italy & 12.80 & 45.83 & 100 \\
\hline IT5 & Ba13463 & Italy & 13.15 & 45.75 & 1 \\
\hline IT6 & Ba13470 & Italy & 11.77 & 45.55 & 100 \\
\hline IT7 & Ba8590 & Italy & 7.58 & 45.02 & 270 \\
\hline IT8 & Ba8596 & Italy & 7.47 & 44.33 & 700 \\
\hline IT9 & Ba8617 & Italy & 10.29 & 46.49 & 1846 \\
\hline IT10 & Ba8622 & Italy & 7.04 & 45.14 & 300 \\
\hline IT11 & Ba11902 & Italy_Sardegna & 9.37 & 40.22 & 1000 \\
\hline NL1 & Ba9246 & Netherlands & 7.03 & 53.12 & 0 \\
\hline NO1 & Ba10103 & Norway & 5.67 & 58.72 & 50 \\
\hline NO2 & Ba10111 & Norway & 5.33 & 59.92 & 10 \\
\hline NO3 & Ba10113 & Norway & 6.63 & 61.18 & 75 \\
\hline PL1 & Ba11427 & Poland & 20.95 & 51.68 & 100 \\
\hline PL2 & Ba11429 & Poland & 20.65 & 50.85 & 300 \\
\hline PL3 & Ba11431 & Poland & 20.67 & 50.87 & 270 \\
\hline PL4 & Ba11449 & Poland & 20.57 & 49.42 & 700 \\
\hline PL5 & Ba11453 & Poland & 20.30 & 49.40 & 500 \\
\hline PT1 & Ba13099 & Portugal & -6.82 & 41.88 & 841 \\
\hline PT2 & Ba13101 & Portugal & -6.98 & 41.80 & 444 \\
\hline PT3 & Ba13104 & Portugal & -7.78 & 41.82 & 1133 \\
\hline PT4 & Ba13132 & Portugal & -9.15 & 39.37 & 28 \\
\hline RO1 & Ba9971 & Romania & 26.33 & 47.45 & 350 \\
\hline RO2 & Ba9984 & Romania & 21.82 & 46.98 & 100 \\
\hline RO3 & Ba9990 & Romania & 25.80 & 45.85 & 600 \\
\hline Sct1 & Ba14025 & Scotland & -7.52 & 57.60 & 15 \\
\hline Sct2 & Ba14026 & Scotland & -8.56 & 57.81 & 10 \\
\hline Sct3 & Ba14053 & Scotland & -6.03 & 57.22 & 5 \\
\hline SK1 & Ba11887 & Slovakia & 19.42 & 48.82 & 650 \\
\hline TR1 & Ba9123 & Turkey & 42.04 & 41.12 & 1210 \\
\hline TR2 & Ba9151 & Turkey & 30.39 & 40.78 & 110 \\
\hline Wal1 & Ba10951 & Wales & -3.63 & 52.61 & 180 \\
\hline Wal2 & Ba12142 & Wales & -4.68 & 52.12 & 40 \\
\hline Wal3 & Ba14027 & Wales & -4.05 & 52.51 & 0 \\
\hline Wal4 & Ba9791 & Wales & -4.08 & 52.42 & 100 \\
\hline Wal5 & Ва9799 & Wales & -3.78 & 51.90 & 100 \\
\hline
\end{tabular}

(accession GDAT00000000) and $\mathrm{Y}$ is the base position of the SNP within that contig. Users may freely employ these probes in their own assays; alternatively IBERS offer access to the existing array as a genotyping service (contact corresponding author).

\section{Genetic diversity analysis}

Data exported from Genome Studio (Illumina) were converted to allele specific presence. For the $A$ alleles for each $\mathrm{SNP}, \mathrm{AA}$ individuals were coded as $1, \mathrm{AB}$ as 0.5 and $\mathrm{BB}$ and missing data were 0 , and vice versa for the $\mathrm{B}$ alleles.
Missing data were, therefore, coded as 0 for both the A and $\mathrm{B}$ alleles and were, therefore, not imputed. Allele frequencies for each marker within accessions were calculated by summing the values for the genotypes (as described above) for each individual within an accession for each SNP and divided by the number of individuals in the accession. Principal component analysis (PCA) was performed on these relative allele frequencies using $\mathrm{R}$ (version 2.15.3). Markers contributing the most to PC1 and PC2 were identified via the absolute loading of each marker to the respective PC. For each PC, the BLASTx annotation for the top 50 markers was investigated (Tables 3, 4). 
Diversity measures were calculated within each of the accessions using GenAlEx (Peakall and Smouse 2006). Distribution of variation between geographic regions (as observed and defined following PCA and Supplementary Fig. 1) between accessions and within accessions was calculated using AMOVA within GenAlEx. This was reported as percentage of variation and measures of $\mathrm{Phi}_{\mathrm{PT}}$. $\mathrm{Phi} \mathrm{PT}_{\mathrm{PT}}$ is used for codominant data as it suppresses intra-individual variation (Teixeira et al. 2014). AMOVA between neighbouring regions was also performed, treating each region as a single population ( $1 \mathrm{df}$ ) to compare to a previous study speculating at the divergence pattern and migration of $L$. perenne across Europe (McGrath et al. 2007).

Population structure was inferred using an unbiased Bayesian approach Markov chain Monte Carlo (MCMC) clustering of samples via STRUCTURE v2.3.4 (Pritchard et al. 2000). The data were assessed for prior values of $K$ ranging from 1 to 10 with burnin and MCMC iterations settings at 25,000 and 25,000, respectively. For each value of $K, 3$ replications were performed. STRUCTURE Harvester v.0.6.93 was then used to identify the optimal value of $K$ (using $\Delta K$ value; second-order rate of change in log probability between successive values of $K$ ) (Earl and VonHoldt 2012) with CLUMPP used to generate a consensus between runs (Supplementary Fig. 2). Probability of individual membership to group 1 was used to correlate with longitude of sample site origin.

\section{Results}

\section{Performance of the array}

The Lolium Infinium beadchip assayed 2185 markers with call rates that exceeded $99 \%$ in 86 out of 90 ecotype accessions. The remaining four accessions had average call rates ranging from 97.8 to $98.7 \%$. As these call rates were consistent between individuals in the accession and across sample replicates, these data were included. Reproducibility of sample replicates was extremely high, with accuracy greater than $99.9 \%$.

\section{Genetic diversity}

The Infinium platform was used to quantify the diversity present in 90 geographically referenced ecotype accessions, represented by 716 individual genotypes, spanning 21 countries and across a range of geographical conditions in Europe (Table 1). As seed for each sample site was germinated and polycrossed within accession at Aberystwyth seed bank, the individuals from each accession would be expected to display greater observed heterozygosity than expected under normal population genetics assumptions due to the self-incompatibility complex in L. perenne. The allele frequencies across individuals in an accession (population), however, are representative of those in the sampled location. Allele frequency was, therefore, used to represent the sample locations across Europe in analyses.

The distribution of the genetic variation was also considered and partitioned based on the outcome of the PCA and geographic-genetic correlations (see below; Fig. 1a; Supplementary Fig. 1). The variation was compared between four regions, between accessions within region and between individuals within accessions using Phi (analogous to $F_{\mathrm{ST}}$ ). The regions were defined by groupings observed in the PCA plot (Supplementary Fig. 1). Whilst some genetic variation was partitioned between regions, the greatest diversity (68\%) was attributed to between individuals within an accession (Table 2). Phi ${ }_{\mathrm{PT}}$ showed greater variation between populations within regions $\left(\mathrm{Phi}_{\mathrm{PR}}\right)$, compared to between regions $\left(\mathrm{Phi}_{\mathrm{RT}}\right)$. A more focused analysis of the distribution of variation between the different regions found similar levels (73-74\%) of within accession variation in the East and West group. The greatest within-population variation was found in the North group, at $76 \%$, and the least variation in the South $(69 \%)$. The regional Phi values reflect the between-population variation and indicate that this is highest in among accessions in the Southern group.

\section{Population structure in European Lolium perenne ecotypes}

To understand the broad genetic diversity and distribution across Europe, unbiased PCA was performed on the allele frequency for each of the 2185 SNPs within each of the 90 sample locations (accession) (Fig. 1a). PCA uses no prior information on the genotypes in construction of the plot, but despite this the observed distribution bears a striking resemblance to the geographic distribution of the original sampling sites. An East-West distribution was observed on $\mathrm{PC} 1$, in addition to a strong $\mathrm{UK}$ and Iberian divide on PC2. A strong correlation $\left(R^{2}\right)$ of 0.798 was found for PC1 to longitude $(P<0.001)$ and 0.712 for $\mathrm{PC} 2$ to latitude $(P<0.001)$ (Fig. 1b, c). Significant correlations were also observed between altitude and PC2 $(-0.347, P<0.001)$. Ecotypes from the UK were found to cluster in the upper left quadrant of the PCA plot, with particular similarity of accessions originating from England and Ireland. Accessions from Scottish islands and Wales were more divergent. A strong Iberian cluster was observed, with exception of one Portuguese accession (PT4; Ba13132) and the inclusion of an Italian accession (IT6; Ba13470). The centre of the PCA plot shows divergence of accessions along PC2 approximately split by the Alps Mountain range. Accessions originating from Eastern Europe are found on the 


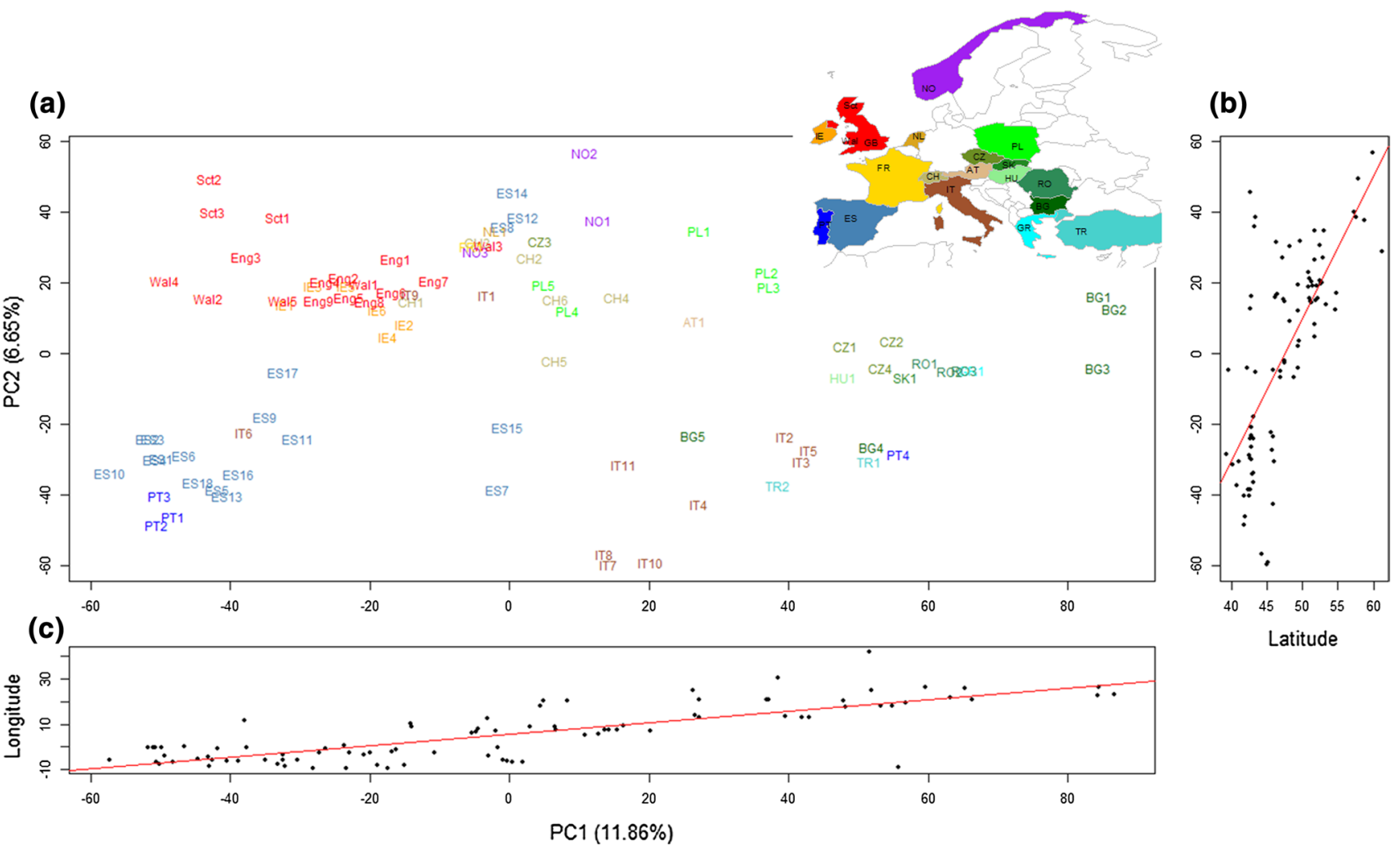

Fig. 1 Principal component analysis of the allele frequencies of 90 ecotype accessions (with eight individuals) from 20 countries based on PC1 and PC2. a PC1 v PC2; small coloured labels represent each accession. Inset map provides key to labels. AT Austria, $B G$ Bulgaria, CH Switzerland, CZ Czech Republic, ES Spain, FR France, Eng England, $G R$ Greece, $H U$ Hungary, $I E$ Ireland, $I T$ Italy, $N L$ Netherlands,
NO Norway, PL Poland, PT Portugal, RO Romania, Sct Scotland, SK Slovakia, TR Turkey, Wal Wales. b Correlation plot of PC2 with latitude of original seed sample site. Correlation coefficient, $R^{2}=0.712$, $P<0.0001$. c Correlation plot of PC1 with longitude of original seed sample site. Correlation coefficient, $R^{2}=0.798, P<0.0001$ right hand side of the plot, with particular extremity shown by those collected from Bulgaria.

The population structure of the European ecotypes was also examined using STRUCTURE. The optimal number of subgroups $(\mathrm{K})$ within this large collection of individuals was found using Structure Harvester to be two (Supplementary Fig. 2). These data are presented as a scatterplot of individual genotype probability of membership to group plotted against the longitude of the sample site (Fig. 2). In agreement with the PCA, there was significant strong correlation of probability of group membership to longitude $\left(R^{2}=0.782, P<0.001\right)$. The notable outlier (small probability of group 1 membership and low longitude value) was PT4, which was expected given the clustering in the PCA plot (Fig. 1). A small secondary peak was also observed at 4 subgroups (Supplementary Fig. 2). Two of these groups had significant correlation to longitude $\left(R^{2}=0.766, P<0.001\right)$ and latitude $\left(R^{2}=0.737\right.$, $P<0.001)$. The probability of an individual's group membership was averaged for each region, as defined by the PCA plot (Supplementary Fig. 1). High probabilities were found for each group (group 1, average probability to South region of 0.57 ; group 2 to North region of 0.59 ; group 3 to East region of 0.72 ; group 4 to West region of 0.80 ) suggesting that the secondary peak at $K=4$ was reflective of the PCA plot.

\section{Identification of primary genetic-geographic markers}

To identify the markers contributing to the most prominent genetic structure and variation, the top 50 markers (as determined by their loading) for PC1 and PC2 were identified (Tables 3, 4). Markers within the same contig were commonly seen to have a similar rank within a principal component. This occurred for contigs 35543, 40624 and 7394 in the top 50 of PC1 and for 7 contigs in the top 50 markers contributing to $\mathrm{PC} 2$, indicative of closely linked markers behaving similarly as would be expected for robust array SNP probes. The BLASTx annotation for the contigs in which these markers were located was then assessed to determine if putative adaptive transcripts could be identified. Further showing that transcript/loading associations 
Table 2 Summary of diversity described in European ecotypes by AMOVA

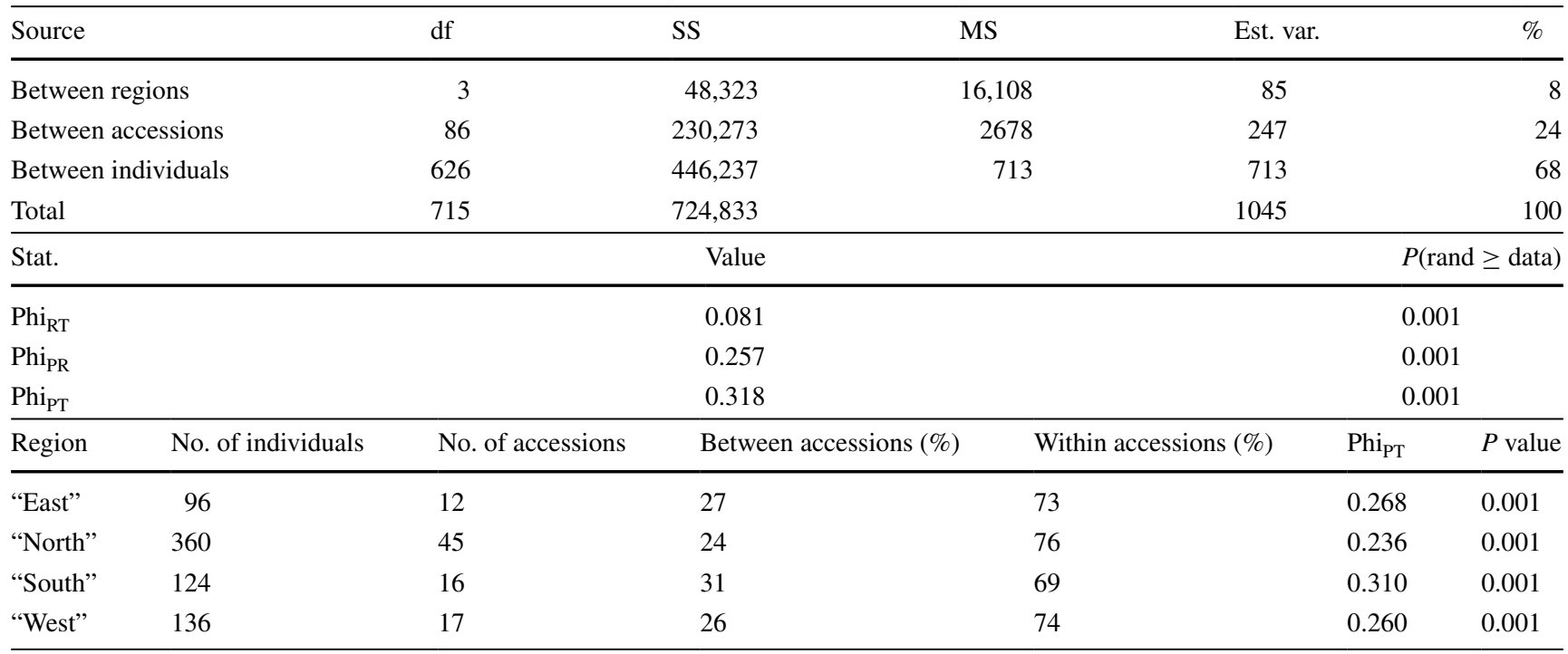

$D f$ degrees of freedom; $\mathrm{SS}$ sum of squares, $M S$ mean square, Est var. estimated variance. $\mathrm{Phi}_{\mathrm{RT}}=\mathrm{AR} /(\mathrm{WP}+\mathrm{AP}+\mathrm{AR})=\mathrm{AR} / \mathrm{TOT}$ among regions . $\mathrm{Phi}_{\mathrm{PT}}=(\mathrm{AP}+\mathrm{AR}) /(\mathrm{WP}+\mathrm{AP}+\mathrm{AR})=(\mathrm{AP}+\mathrm{AR}) / \mathrm{TOT}($ among individuals within accessions $) . \mathrm{Phi}_{\mathrm{PR}}=\mathrm{Phi} \mathrm{RT}_{\mathrm{RT}}+\mathrm{Phi} \mathrm{PR}_{\mathrm{PR}}=\mathrm{AP} / \mathrm{WP}+\mathrm{AP}$ (among accessions within region) where AR is between regions; AP is between accessions within region; WP is between individuals within accession

Individuals divided into four regions as described by PCA (Fig. 1 and defined in Supplementary Fig. 1). Regions described as "North"-upper quadrant of PCA plot including individuals from the UK, Northern Europe and Spanish outliers. "West"-bottom left group comprised of individuals from Spanish and Portuguese sample sites. "South"-bottom quadrant comprising Italian, Bulgarian and Turkish individuals. "East" group describes individuals on centre right of PCA plot, including Romania, Czech Republic, Bulgaria

Fig. 2 STRUCTURE analysis of ecotypes based on 2185 SNPs for $K=2$, with probability of membership to group 1 shown against longitude of sample site. Optimal value of $K$ determined using STRUCTURE Harvester. The consensus probability of group membership, as determined using CLUMPP, is plotted against the longitude of the sample site for each individual. Correlation of longitude to group 1 membership; $R^{2}=-0.7815$

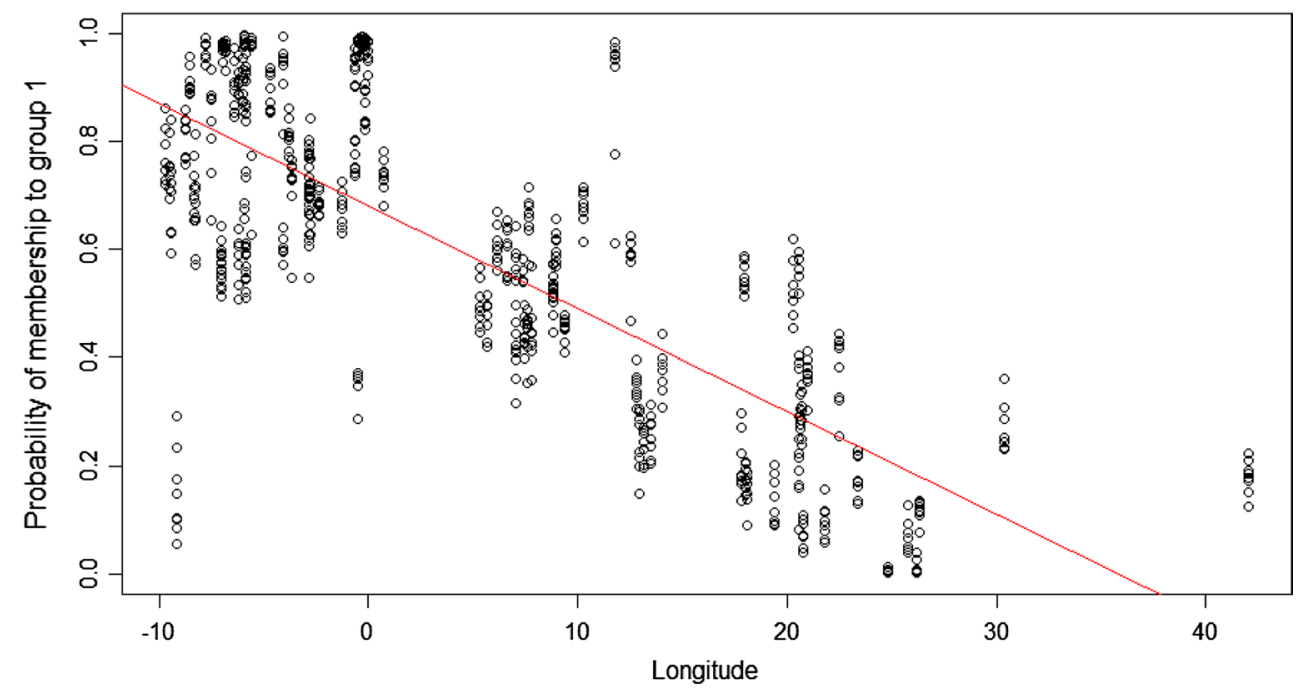

were robust, we observed that several contigs had the same annotation: for example, contigs 35,543 and 40,624 (Table 3) both returned a hit to formate-tetrahydrofolate ligase, and this was represented by 6 markers in the top 50 for PC1. A similar occurrence was seen for PC2 with an aarF domain containing protein kinase identified as a best hit from 3 markers contained in 2 contigs (7729 and 49,805).

\section{Discussion}

\section{Creation of an SNP resource for Lolium perenne}

Based on NGS transcriptome sequencing, we have created a publically available resource of 2185 high-quality genetic markers which can be used for rapid genotyping of $L$. perenne. This significantly increases the number of 
Table 3 Top 50 markers contributing to the loading on PC1

\begin{tabular}{|c|c|c|}
\hline Marker & PC1 & BLAST \\
\hline Contig33338_1322 & 0.049 & Major facilitator superfamily domain-containing protein 5 -like \\
\hline Contig53271_67 & 0.046 & NA \\
\hline Contig49873_302 & 0.046 & Histidine-containing phosphotransfer protein 2 \\
\hline Contig35543_1175 & 0.045 & Formate-tetrahydrofolate ligase-like \\
\hline Contig17494_1000 & -0.044 & Glucan endo-1_3-beta-glucosidase GV \\
\hline Contig34149_1405 & 0.044 & $\mathrm{PP}$ \\
\hline Contig42055_156 & -0.044 & PP \\
\hline Contig40624_321 & 0.043 & Formate-tetrahydrofolate ligase-like \\
\hline Contig40624_549 & -0.043 & Formate-tetrahydrofolate ligase-like \\
\hline Contig7394_1265 & -0.043 & $66 \mathrm{kDa}$ stress protein-like \\
\hline Contig7394_878 & -0.042 & $66 \mathrm{kDa}$ stress protein-like \\
\hline Contig35543_365 & 0.042 & Formate-tetrahydrofolate ligase-like \\
\hline Contig32759_449 & -0.040 & Protein RER1B-like \\
\hline Contig50617_428 & -0.040 & Reticulon-like protein B8-like \\
\hline Contig8691_750 & -0.040 & $\mathrm{PP}$ \\
\hline Contig9865_491 & 0.040 & PP \\
\hline Contig52098_89 & -0.040 & Farnesylated protein 2 [Hordeum vulgare subsp. vulgare] \\
\hline Contig43816_303 & -0.040 & Hypothetical protein SORBIDRAFT \\
\hline Contig40661_72 & -0.040 & GSK-like kinase [Triticum aestivum] \\
\hline Contig36221_1388 & 0.040 & $\mathrm{PP}$ \\
\hline Contig10390_1015 & -0.039 & $\mathrm{PP}$ \\
\hline Contig37988_1071 & -0.039 & PP \\
\hline Contig6836_1026 & -0.039 & Malonyl-CoA-acyl carrier protein transacylase_mitochondrial-like \\
\hline Contig7723_139 & -0.039 & Methionine aminopeptidase 1A-like \\
\hline Contig43968_560 & -0.039 & cycloartenol synthase \\
\hline Contig31420_213 & -0.039 & Importin subunit alpha-1a-like \\
\hline Contig16521_537 & -0.038 & Laccase LAC5-4 [Lolium perenne $]$ \\
\hline Contig40828_1699 & -0.038 & NPH1-2 \\
\hline Contig6666_679 & 0.038 & PP \\
\hline Contig45469_388 & 0.038 & PP \\
\hline Contig32047_1499 & 0.038 & PP \\
\hline Contig10442_410 & -0.038 & $\mathrm{PP}$ \\
\hline Contig6744_927 & -0.037 & Adenylyl cyclase-associated protein-like \\
\hline Contig50264_1001 & -0.037 & $\mathrm{PP}$ \\
\hline Contig32202_682 & -0.037 & PP \\
\hline Contig15977_1173 & -0.036 & Chromosome-associated kinesin KIF4-like \\
\hline Contig6744_417 & -0.036 & Adenylyl cyclase-associated protein-like \\
\hline Contig35543_281 & -0.036 & Formate-tetrahydrofolate ligase-like \\
\hline Contig35543_641 & -0.036 & Formate-tetrahydrofolate ligase-like \\
\hline Contig36358_326 & -0.036 & $\mathrm{PP}$ \\
\hline Contig7673_909 & -0.036 & PP \\
\hline Contig7054_239 & 0.036 & $\mathrm{PP}$ \\
\hline Contig49944_954 & -0.036 & Gamma-tocopherol methyl transferase [Triticum aestivum] \\
\hline Contig41068_335 & 0.035 & PP \\
\hline Contig20240_138 & 0.035 & $\mathrm{PP}$ \\
\hline Contig31682_1562 & -0.035 & BEL1-like homeodomain protein 6-like \\
\hline Contig51006_260 & -0.035 & Ribosome biogenesis protein NSA2 homologue \\
\hline Contig50500_372 & -0.035 & $\mathrm{PP}$ \\
\hline Contig51969_109 & -0.035 & $\mathrm{PP}$ \\
\hline Contig51913 371 & 0.035 & PP \\
\hline
\end{tabular}

$N A$ not available (no BLAST result), $P P$ predicted protein 
Table 4 Top 50 markers contributing to the loading on PC2

\begin{tabular}{|c|c|c|}
\hline Marker & PC2 & BLAST \\
\hline Contig31170_2438 & -0.057 & $\mathrm{PP}$ \\
\hline Contig17179_1421 & -0.057 & Cysteine proteinase 1-like \\
\hline Contig31170_1515 & -0.056 & $\mathrm{PP}$ \\
\hline Contig40677_129 & -0.052 & Delta(24)-sterol reductase-like \\
\hline Contig31170_798 & 0.052 & PP \\
\hline Contig49805_880 & -0.051 & Uncharacterized aarF domain-containing protein kinase \\
\hline Contig40677_1150 & -0.050 & $\operatorname{Delta}(24)$-sterol reductase-like \\
\hline Contig6946_62 & -0.049 & $\mathrm{PP}$ \\
\hline Contig52497_155 & -0.049 & NA \\
\hline Contig7729_241 & -0.047 & Uncharacterized aarF domain-containing protein kinase \\
\hline Contig6714_427 & 0.046 & $\mathrm{PP}$ \\
\hline Contig9365_585 & -0.045 & $\mathrm{PP}$ \\
\hline Contig41380_775 & -0.045 & Putative cytochrome $\mathrm{P} 450$ [Lolium rigidum] \\
\hline Contig40621_1539 & -0.043 & PP \\
\hline Contig7958_544 & 0.043 & Isoflavone reductase \\
\hline Contig16471_106 & 0.043 & $\mathrm{PP}$ \\
\hline Contig49805_127 & -0.041 & Uncharacterized aarF domain-containing protein kinase \\
\hline Contig6632_2269 & 0.041 & $\mathrm{PP}$ \\
\hline Contig31122_190 & 0.040 & PP \\
\hline Contig6914_70 & 0.040 & PP \\
\hline Contig31167_1317 & -0.040 & Myosin-J heavy chain-like \\
\hline Contig32310_158 & -0.040 & Pyruvate dehydrogenase E1 component subunit alpha-like \\
\hline Contig35649_435 & 0.039 & Trehalose-6-phosphate synthase \\
\hline Contig44219_328 & 0.039 & $\mathrm{PP}$ \\
\hline Contig50225_614 & 0.038 & Zinc finger $\mathrm{CCCH}$ domain-containing protein 49 -like \\
\hline Contig35863_78 & -0.037 & Acyl-coenzyme A oxidase 3_peroxisomal-like \\
\hline Contig6855_1933 & -0.037 & $\mathrm{PP}$ \\
\hline Contig8527_579 & 0.037 & PP \\
\hline Contig31167_864 & -0.037 & Myosin-J heavy chain-like \\
\hline Contig37468_683 & 0.037 & CBL-interacting protein kinase 2-like \\
\hline Contig52209_230 & 0.037 & Putative cytochrome $\mathrm{P} 450$ [Lolium rigidum $]$ \\
\hline Contig31242_1073 & -0.037 & Hydroquinone glucosyltransferase_putative_expressed \\
\hline Contig49802_385 & -0.036 & Transcription factor Pur-alpha 1-like \\
\hline Contig9232_399 & 0.036 & PP \\
\hline Contig52297_289 & -0.036 & $\mathrm{PP}$ \\
\hline Contig40957_743 & -0.036 & Annexin D5-like \\
\hline Contig40660_160 & -0.036 & Cell division cycle protein 48_putative_expressed \\
\hline Contig18648_66 & -0.036 & NA \\
\hline Contig50193_695 & -0.036 & $\mathrm{PP}$ \\
\hline Contig42143_365 & 0.036 & NA \\
\hline Contig53284_164 & 0.036 & PP \\
\hline Contig41676_341 & -0.035 & PP \\
\hline Contig6632_1814 & 0.035 & PP \\
\hline Contig50143_1456 & -0.035 & Delta-1-pyrroline-5-carboxylate synthase-like \\
\hline Contig35084_2381 & -0.035 & Villin-2-like isoform 1 \\
\hline Contig7244_936 & -0.035 & PP \\
\hline Contig13040_111 & -0.035 & $\mathrm{PP}$ \\
\hline Contig7101_762 & -0.035 & Hypothetical protein SORBIDRAFT_10g007850 \\
\hline Contig7394_1265 & 0.035 & $66 \mathrm{kDa}$ stress protein-like \\
\hline Contig7394_878 & 0.035 & $66 \mathrm{kDa}$ stress protein-like \\
\hline
\end{tabular}

$N A$ not available (no BLAST result), $P P$ predicted protein 
SNPs assayed on a single array from the previously published 768-plex Illumina GoldenGate array (Studer et al. 2012), which are complementary with our marker set (a v2 assay is being developed with many of these SNPs included). The assay described in this paper provides a new resource to elucidate the selective forces operating on the genomes of naturally occurring perennial ryegrass. A better understanding of these evolutionary forces will have implications for the development of new resilient grassland systems in the context of climate smart agriculture. A publically available SNP genotyping resource will also enable a population-based approach to conservation genetics and higher resolution study of the population structure of $L$. perenne. Conversion of NGS transcriptome sequence variants into validated SNP probes was $\sim 64 \%$ successful, which appears to be consistent with similar assays based on NGS data (van Bers et al. 2012; Verde et al. 2012). Given the de novo nature of this transcriptome assembly, the heightened stringency measures taken in selecting putative SNPs was indeed necessary and, if repeated, could now take into account the existence of recent, more in-depth NGS assemblies such as the annotated transcriptome of Ruttink et al. (2013) or the draft $L$. perenne genome currently in progress. Regardless, the assay represents a significant increase in SNP resources for Lolium and highlights the value of developing fixed platforms which can be used to assay the same markers across a broad range of material.

\section{Population structure of Lolium perenne across Europe}

This study reveals the genetic structure of European $L$. perenne populations and demonstrates strong correlations between genotypes and geographic origin despite no prior knowledge. Previous studies on L. perenne have reported a population structure (Skot et al. 2005; Yu et al. 2011; Bolaric et al. 2005a, b; McGrath et al. 2007; Balfourier et al. 1998, 2000). Balfourier et al. $(1998,2000)$ reported an association of geographic origin to genetic diversity, initially via 120 populations but only across 12 loci marker set and then from 28 populations using cpDNA identifying 15 haplotypes. Similar results were reported by McGrath et al. (2007). However, the link to geography has not been as clearly defined as in this study. Our results provide a greater resolution as a consequence of a larger marker set and sample size. Similar genetic-geographic correlations have been seen previously across Europe in $>3000$ human genotypes with a high density (500 k) SNP array (Novembre et al. 2008). Substructuring of $L$. perenne populations due to geography may be indicative of either adaptation to different ecological habitats, or due to changes in allele frequency resulting from population subdivision (i.e. isolations by distance and/or from glacial refugia): potentially a mixture of both. Divisions of the L. perenne population across both latitudinal and longitudinal gradients have been proposed previously in limited sample population sizes and with a reduced marker set using isozyme analysis (Balfourier et al. 1998) and chloroplast DNA haplotyping (Balfourier et al. 2000). L. perenne has been suggested to have arisen in the Middle East and subsequently migrated to Europe, with the Alps acting as a barrier to gene flow between North and South Europe (Balfourier et al. 1998, 2000). However, this scenario would be expected to result in a diversity gradient from West to East due to the sequential sampling of allele frequencies from the wave of advance and result in lower diversity in the Western regions. This study, however, found comparable diversity between accessions in East and West regions (Table 2), which does not support this theory.

The alternative scenario is one of the repeated population expansion and contraction due to periodic glacial cover, in which $L$. perenne populations were forced back to Western, Eastern and Central refugia along the Mediterranean prior to subsequent re-expansion to Northern latitudes. Populations in each refugium diverge during the glacial maxima and then interact with divergent allele frequencies mixing in areas of expansion overlap, resulting in clines that run approximately East to West. Our study supports this scenario due to comparable diversity in East and West regions, and greater diversity in the Central/Southern region and lowest between accession diversity in the North as indicated by $\mathrm{Phi}_{(\mathrm{PT})}$ (Table 2).

Evidence has also been previously provided to support the migration from South to North Europe via comparisons of geographic groups using AMOVA, whereby no variation was found between Near Eastern and Southern European ecotypes, nor Western and Southern European ecotypes (McGrath et al. 2007). AMOVA on these data between neighbouring regions identified variation between all neighbouring populations (Supplementary Table 1) unlike the previous study. McGrath et al. (2007) also found no variation when comparing populations north and south of the Alps. In this study, despite the close geographic proximity of some accessions in northern Italy and Switzerland, the genetic divide is disproportionately large, as observed from PCA, supporting the theory of a physical population barrier dictated by the altitude of the Alps. The differing results are probably a reflection of number of markers used and number of sample populations used, together these have given a greater resolution of genetic diversity and association with geography.

Two ecotypes, PT4 and IT6, were found to be outliers based on their genotypes, compared to their geographic origin (Fig. 1). Their actual geographic sample site was found to be of low altitude and coastal. Therefore, it is proposed that these ecotypes may have been transported via (sea) trade routes from their "genetic" origin to their current geographic location. PT4 (Ba13132) has previously found to 
be genetically outlying from other $L$. perenne Portuguese accessions based on AFLP analysis (Cresswell et al. 2001), supporting the results in this study. This suggests that the resolution of the SNP resource offers the potential to distinguish recent migrations due to human activity from those undergone as the species spread from refugia.

This study, as one of creation, validation and investigation of $L$. perenne ecotype diversity, has been able to unexpectedly provide a greater resolution of the European colonisation of perennial ryegrass, which deserves further and more detailed analysis. This, coupled to chloroplast data, may answer some of the questions regarding the migration history of $L$. perenne raised by Balfourier et al. (1998, 2000).

\section{Diversity of ecotypes}

The greatest proportion of the variation identified in this large ecotype collection was found between individual plants (Table 2). This is not unexpected due to the outbreeding nature and the self-incompatibility complex in $L$. perenne (Thorogood et al. 1993). It is also comparable to between individual variation of 61 and $82 \%$ previously found in European and Irish $L$. perenne ecotypes, respectively, based on cytoplasmic markers across 78 accessions (McGrath et al. 2007). Bolaric et al. (2005b) also reported $68 \%$ within European cultivars and $74 \%$ within Polish ecotypes.

\section{Identification of markers contributing to geographic division}

A number of markers within the same contigs were identified as having a similar loading to a principal component, as would be expected in the case of genuine associations of genotype with geographic location. This was highlighted by examples in the top 50 markers for PC1 and PC2 in Tables 3 and 4, but was common through the rankings. Markers associated with the East-West divide (PC1) are listed in Table 3. To identify transcripts putatively associated with the geographic split and thus possibly adaptive variation, the BLASTx annotations of the RNAseq contigs from which these markers were derived were investigated further. Whilst a majority of the sequences returned no hit or hits to predicted proteins only, several contigs were identified which may be indicative of adaptation to environment. These included six SNPs across two contigs having a greatest similarity to formate tetrahydrofolate ligase, which has been associated with $\mathrm{CO}_{2}$ metabolism (Dupont 2008) and to photorespirational response to stress (Cai et al. 2011). Subsequent analysis has demonstrated that these two contigs are actually the same transcript, overlapping by 20 bases (which would have been insufficient for contig merging in the assembly parameters used here). Reassembly of contigs to a draft $L$. perenne genome sequence is ongoing and annotations will be updated accordingly. Several other transcripts showed multiple markers associated with the PC1 divide: adenylyl cyclase-associated protein and a $66 \mathrm{kDa}$ stress-related protein both had two SNPs within the same contig present in the top 50 markers. The former of these has been associated with auxin-regulated cell proliferation (Ichikawa et al. 1997) and also in blue light signalling (Iseki et al. 2002) - another marker in a transcript encoding NPH1-2 is associated with blue light response (Sakai et al. 2011). The $66 \mathrm{kDa}$ stress-related protein has a WD40 functional domain, which has been linked to developmental signalling pathways in plants (van Nocker and Ludwig 2003). Interestingly, the same markers within this latter transcript also appear in the top 50 contributing to PC2, suggesting a strong association of the transcript with geographic diversity. Other transcripts associated with developmental pathways and/or stress responses are also observed to contribute to $\mathrm{PC} 1$ : histidine-containing phosphotransfer protein 2 has been demonstrated to play a role in cytokinin signalling in Arabidopsis (Hutchison et al. 2006), whilst GSK-like kinases are known to be involved in multiple developmental and stress signalling pathways in plants (Choe et al. 2002). A transcript encoding gammatocopherol methyl transferase was also identified: tocopherols are essential micronutrients in plants and act to protect against oxidative stress (Koch et al. 2003). Several transcripts involved in import/export are also identified (major facilitator superfamily protein, importin subunit), along with transcripts involved in cell wall lignification (laccase).

Markers contributing to PC2, or the North-South axis, tell a similar story. Markers were identified in transcripts linked to plant growth/development: cysteine proteinase (Grudkowska and Zagdanska 2004), Pur-alpha transcription factor (a general regulator of cell cycle gene expression; Trémousaygue et al. 2003) and a cell division cycle protein. Stress-related transcripts are also identified, including the same $66 \mathrm{kDa}$ protein as for PC1. Two markers are identified in a contig encoding an aarF/ABC1 domain protein: interestingly, this family of proteins has been implicated in tocopherol biosynthesis, a process also putatively affected in PC1 and a possible response to oxidative stress (Martinis et al. 2013). A transcript encoding delta(24)sterol reductase was also identified: again, sterols play a role in antioxidant activity in plants (Wang et al. 2012) and cycloartenol synthase (involved in the production of sterol intermediates) was also identified on PC1. Hydroquinone glucosyltransferase was also identified on PC2 and phenolic hydroquinones also have antioxidant properties, suggesting a putative general role for these compounds in plant adaptation. It should be noted that sterol levels also play a role in cold tolerance in plants (Palta et al. 1993), and we also observe a marker in a transcript encoding a 
trehalose-6-phosphate synthase, which is also implicated in cold tolerance ( $\mathrm{Li}$ et al. 2011). Finally, and distinct to the observations for PC1, several transcripts were observed to be involved in cytoskeletal development (myosin, villin) and $\mathrm{Ca}^{2+}$-mediated signalling (CBL-interacting protein, annexin).

The pathways identified on both PC1 and PC2 are all strong candidates for adaptational responses to environment. However, further research will be needed to see if specific haplotypes are indeed associated with phenotypic changes that would suggest adaptation. It is also possible that these markers represent founder effects as the L. perenne subpopulations spread from refugia.

\section{Potential applications of the iSelect assay}

This analysis, based on genome-wide nuclear marker technology, improves the resolution with which the population substructure can be assessed, offering a clearer understanding of how the migration of L. perenne across Europe may have occurred. In addition, there is potential to identify the genomic regions strongly differentiating the different subpopulations and thus untangling the effects of migration and adaptation. This latter point is of particular importance in the face of global issues of climate change and food security-if the geographic correlations observed are tied to ecological habitat, then genomic regions can potentially be identified that are involved in local adaptation which can be mined for useful traits needed in $L$. perenne breeding programmes (and possibly used for gene discovery in other grasses). The next steps will be to identify the extent of linkage disequilibrium within $L$. perenne to determine the power of this marker set to perform genome-wide association studies (GWAS) of adaptive traits, as well as to determine the amount of ecological diversity which has been captured within existing breeding programmes. Large-scale genotyping has the potential to significantly improve the rationale of conservation, characterisation and utilisation of crop genetic resources (McCouch et al. 2012). In the case of perennial ryegrass, the iSelect array developed in this study can potentially be used to explore existing variation in ryegrass collections, manage seed multiplication and enhance quality control procedures. This assay also provides a means to identify core collections for ryegrass ecotypes for multi-environment field testing to identify candidate genes underlying quantitative traits responsible for adaptation to changing climatic conditions.

\section{Conclusion}

This publically available resource significantly expands on the marker density previously available for genotyping the agriculturally important forage crop species, L. perenne. The validated markers have allowed a greater resolution of the genetic-geographic population structure and diversity available in the ecotypic population in Europe. These populations, along with the array, will provide a mechanism to identify the markers, genes and traits to respond to the demands of a rapidly changing climate.

Author contribution statement WP \& MH designed the research. MH conducted the NGS analysis, SNP discovery and assay design. TB conducted genotyping and genetic diversity analyses. RM advised on population genetics analysis. TB, MH \& WP wrote the paper. RM provided critical review of the paper. IT collected, stored and catalogued germplasm for the ecotype collection.

Acknowledgments We would like to acknowledge the substantial contributions of John Harper and Dagmara Gasior of IBERS who maintained the ecotype collections. Next-generation DNA sequencing was performed by the Edinburgh GenePool (http://genepool.bio.ed.ac. $\mathrm{uk} /$ ). Work in our group was funded partially via the Biotechnology and Biological Sciences Research Council.

Conflict of interest The authors declare that they have no conflict of interest.

Ethical statement The authors declare that the experiments described in this manuscript comply with the current laws of the UK.

Open Access This article is distributed under the terms of the Creative Commons Attribution 4.0 International License (http://creativecommons.org/licenses/by/4.0/), which permits unrestricted use, distribution, and reproduction in any medium, provided you give appropriate credit to the original author(s) and the source, provide a link to the Creative Commons license, and indicate if changes were made.

\section{References}

Altschul SF, Gish W, Miller W, Myers EW, Lipman DJ (1990) Basic local alignment search tool. J Mol Biol 215:403-410

Baird NA, Etter PD, Atwood TS, Currey MC, Shiver AL, Lewis ZA, Selker EU, Cresko WA, Johnson EA (2008) Rapid SNP discovery and genetic mapping using sequenced RAD markers. PLoS ONE 3(10):e3376. doi:10.1371/journal.pone.0003376

Balfourier F, Charmet G, Ravel C (1998) Genetic differentiation within and between natural populations of perennial and annual ryegrass (Lolium perenne and L. rigidum). Heredity 81:100-110

Balfourier F, Imbert C, Charmet G (2000) Evidence for the phylogeographic structure in Lolium species related to the spread of agriculture in Europe. A cpDNA study. Theor Appl Genet 101:131-138

Bergelson J, Roux F (2010) Towards identifying genes underlying ecologically relevant traits in Arabidopsis thaliana. Nat Rev Genet 11(12):867-879

Bolaric S, Barth S, Melchinger AE, Posselt UK (2005a) Molecular characterization of genetic diversity in European germplasm of perennial ryegrass. Euphytica 146:39-44 
Bolaric S, Barth S, Melchinger AE, Posselt UK (2005b) Molecular genetic diversity within and among German ecotypes in comparison to European perennial ryegrass cultivars. Plant Breeding $124: 257-262$

Brumfield RT, Beerli P, Nickerson DA, Edwards SV (2003) The utility of single nucleotide polymorphisms in inferences of population history. Trends Ecol Evol 18(5):249-256

Cai Y, Cao F, Wei K, Zhang G, Wu F (2011) Genotypic dependent effect of exogenous glutathione on Cd-induced changes in proteins, ultrastructure and antioxidant defense enzymes in rice seedlings. J Hazard Mater 192(3):1056-1066

Choe S, Schmitz RJ, Fujioka S, Takatsuto S, Lee MO, Yoshida S, Feldmann KA, Tax FE (2002) Arabidopsis brassinosteroidinsensitive dwarf12 mutants are semidominant and defective in a glycogen synthase kinase 3beta-like kinase. Plant Physiol 130(3): 1506-1515

Cresswell A, Sackville Hamilton NR, Roy AK, Viegas BMF (2001) Use of amplified fragment length polymorphism markers to assess genetic diversity of Lolium species from Portugal. Mol Ecol 10:229-241

Dupont FU (2008) Metabolic pathways of the wheat (Triticum aestivum) endosperm amyloplast revealed by proteomics. BMC Plant Biol 8:39

Earl DA, VonHoldt BM (2012) STRUCTURE HARVESTER: a website and program for visualizing STRUCTURE output and implementing the Evanno method. Conserv Genet Resour 4(2):359-361

Elshire RJ, Glaubitz JC, Sun Q, Poland JA, Kawamoto K, Buckler ES, Mitchell SE (2011) A robust, simple genotyping-bysequencing (GBS) approach for high diversity species. PLoS ONE 6(5):e19379. doi:10.1371/journal.pone.0019379

Garvin MR, Saitoh K, Gharrett AJ (2010) Application of single nucleotide polymorphisms to non-model species: a technical review. Mol Ecol Resour 10(6):915-934

Grudkowska M, Zagdańska B (2004) Multifunctional role of plant cysteine proteinases. Acta Biochim Pol 51(3):609-624

Hegarty M, Yadav R, Lee M, Armstead I, Scollan N, Powell W, Skot L (2013) Genotyping by RAD sequencing enables mapping of fatty acid composition traits in perennial ryegrass Lolium perenne (L.). Plant Biotechnol J 11:572-581

Huang X, Feng Q, Qian Q, Zhao Q, Wang L, Wang A, Guan J, Fan D, Weng Q, Huang T, Dong G, Sang T, Han B (2009) Highthroughput genotyping by whole-genome resequencing. Genome Res 19(6):1068-1076

Hutchison CE, Li J, Argueso C, Gonzalez M, Lee E, Lewis MW, Maxwell BB, Perdue TD, Schaller GE, Alonso JM, Ecker JR, Kieber JJ (2006) The Arabidopsis histidine phosphotransfer proteins are redundant positive regulators of cytokinin signaling. Plant Cell 18(11):3073-3087

Ichikawa T, Suzuki Y, Czaja I, Schommer C, LeBnick A, Schell J, Walden R (1997) Identification and role of adenylyl cyclase in auxin signalling in higher plants. Nature 390:698-701

Iseki M, Matsunaga S, Murakami A, Ohno K, Shiga K, Yoshida K, Sugai M, Takahashi T, Hori T, Watanabe M (2002) A blue-lightactivated adenylyl cyclase mediates photoavoidance in Euglena gracilis. Nature 415:1047-1051

Jones MB, Donnelly A (2004) Carbon sequestration in temperate grassland ecosystems and the influence of management, climate and elevated $\mathrm{CO}_{2}$. New Phytol 164:423-439

Jones ES, Mahoney NL, Hayward MD, Armstead IP, Jones JG, Humphreys MO, King IP, Kishida T, Yamada T, Balfourier F, Charmet G, Forster JW (2002) An enhanced molecular marker based genetic map of perennial ryegrass (Lolium perenne) reveals comparative relationships with other Poaceae genomes. Genome $45: 282-295$
King J, Roberts LA, Kearsey MJ, Thomas HM, Jones RN, Huang L, Armstead IP, Morgan WG, King IP (2002) A demonstration of a 1:1 correspondence between chiasma frequency and recombination using a Lolium perenne/Festuca pratensis substitution. Genetics 161(1):307-314

Kircher M, Kelso J (2010) High-throughput DNA sequencing-concepts and limitations. BioEssays 32(6):524-536

Koch M, Lemke R, Heise KP, Mock HP (2003) Characterization of gamma-tocopherol methyltransferases from Capsicum annuum $\mathrm{L}$ and Arabidopsis thaliana. Eur J Biochem 270(1):84-92

Li H-W, Zang B-S, Deng X-W, Wang X-P (2011) Overexpression of the trehalose-6-phosphate synthase gene OsTPS1 enhances abiotic stress tolerance in rice. Planta 234(5):1007-1018

Luikart G, England PR, Tallmon D, Jordan S, Taberlet P (2003) The power and promise of population genomics: from genotyping to genome typing. Nat Rev Genet 4:981-993

Martinis J, Glauser G, Valimareanu S, Kessler F (2013) A chloroplast $\mathrm{ABC} 1-$ like kinase regulates vitamin E metabolism in Arabidopsis. Plant Physiol 162(2):652-662

McCouch SR, McNally KL, Wang W, Sackville Hamilton R (2012) Genomics of gene banks: a case study in rice. Am $\mathrm{J}$ Bot 99(2):407-423

McGrath S, Hodkinson TR, Charles TM, Zen DG, Barth S (2007) Variation in inflorescence characters and inflorescence development in ecotypes and cultivars of Lolium perenne L. Grass Forage Sci 65:398-409

Morin PA, Martien KK, Taylor BL (2009) Assessing statistical power of SNPs for population structure and conservation studies. Mol Ecol Resour 9:66-73

Morozova O, Marra MA (2008) Applications of next-generation sequencing technologies in functional genomics. Genomics 92(5):255-264

Novembre J, Johnson T, Bryc K, Kutalik Z, Boyko AR, Auton A, Indap A, King KS, Bergmann S, Nelson MR, Stephens M, Bustamante CD (2008) Genes mirror geography within Europe. Nature 456:98-101

Palta JP, Whitaker BD, Weiss LS (1993) Plasma Membrane Lipids Associated with Genetic Variability in Freezing Tolerance and Cold Acclimation of Solanum Species. Plant Physiol 103(3):793-803

Peakall R, Smouse PE (2006) GENALEX 6: genetic analysis in Excel. Population genetic software for teaching and research. Mol Ecol Notes 6:288-295

Pritchard JK, Stephens M, Donnelly P (2000) Inference of population structure using multilocus genotype data. Genetics 155(2):945-959

Raymond M, Rousset F (1995) GENEPOP (Version 1.2): Population Genetics Software for Exact Tests and Ecumenicism. J Heredity 86(3):248-249

Ruttink T, Sterck L, Rodhe A, Bendixen C, Rouzé P, Asp T, Van de Peer Y, Roldan-Ruiz I (2013) Orthology Guided Assembly in highly heterozygous crops: creating a reference transcriptome to uncover genetic diversity in Lolium perenne. Plant Biotechnol J 11(5):605-617

Sakai T, Kagawa T, Kasahara M, Swartz TE, Christie JM, Briggs WR, Wada M, Okada K (2011) Arabidopsis nph1 and npl1: blue light receptors that mediate both phototropism and chloroplast relocation. Proc Natl Acad Sci USA 98(12):6969-6974

Skot L, Humphreys MO, Armstead I, Heywood S, Skot KP, Sanderson R, Thomas ID, Chorlton KH, Sackville Hamilton NR (2005) As association mapping approach to identify flowering time genes in natural populations of Lolium perenne (L.). Mol Breed $15: 233-245$

Skøt L, Humphreys J, Humphreys MO, Thorogood D, Gallagher J, Sanderson R, Armstead IP, Thomas ID (2007) Association of 
candidate genes with flowering time and water-soluble carbohydrate content in Lolium perenne (L.). Genetics 177(1):535-547

Studer B, Byrne S, Nielsen RO, Panitz F, Bendixen C, Islam MS, Pfeifer M, Lübberstedt T, Asp T (2012) A transcriptome map of perennial ryegrass (Lolium perenne L.). BMC Genom 13(1):140

Syvänen AC (2001) Accessing genetic variation: genotyping single nucleotide polymorphisms. Nat Rev Genet 2(12):930-942

Teixeira H, Rodriguez-Echeverria S, Nabais C (2014) Genetic diversity and differentiation of Juniperus thurifera in Spain and Morocco as determined by SSR. PLoS ONE 9(2):e88996

Thomson MJ (2014) High-throughput SNP genotyping to accelerate crop improvement. Plant Breed Biotechnol 2(3):195-212

Thorogood D, Bowling PJ, Jones RM (1993) Assessment of turf colour change in Lolium perenne L. cultivars and lines. Int Turfgrass Soc Res J 7:729-735

Tilman D, Wedin D, Knops J (1996) Productivity and sustainability influenced by biodiversity in grassland ecosystems. Nature 379:718-720

Trémousaygue D, Garnier L, Bardet C, Dabos P, Hervé C, Lescure B (2003) Internal telomeric repeats and 'TCP domain' proteinbinding sites co-operate to regulate gene expression in Arabidopsis thaliana cycling cells. Plant J 33(6):957-966

Van Bers NEM, Santure AW, Van Oers K, De Cauwer I, Dibbits BW, Mateman C, Crooijmans RP, Sheldon BC, Visser ME, Groenen MAM, Slate J (2012) The design and cross-population application of a genome-wide SNP chip for the great tit Parus major. Mol Ecol Resour 12:753-770 van Nocker S, Ludwig P (2003) The WD-repeat protein superfamily in Arabidopsis: conservation and divergence in structure and function. BMC Genomics 4:50

Verde I, Bassil N, Scalabrin S, Gilmore B, Lawley CT, Gasic K, Micheletti D, Rosyara UR, Cattonaro F, Vendramin E, Main D, Aramini V, Blas AL, Mockler TC, Bryant DW, Wilhelm L, Troggio M, Sosinski B, Aranzana MJ, Arús P, Iezzoni A, Morgante M, Peace C (2012) Development and evaluation of a 9 K SNP array for peach by internationally coordinated SNP detection and validation in breeding germplasm. PLoS ONE 7(4):e35668. doi:10.1371/journal.pone.0035668

Vignal A, Milan D, SanCristobal M, Eggen A (2002) A review on SNP and other types of molecular markers and their use in animal genetics. Genet Select Evol 34(3):275-306

Wang H, Nagegowda DA, Rawat R, Bouvier-Navé P, Guo D, Bach TJ, Chye ML (2012) Overexpression of Brassica juncea wildtype and mutant HMG-CoA synthase 1 in Arabidopsis up-regulates genes in sterol biosynthesis and enhances sterol production and stress tolerance. Plant Biotechnol J 10(1):31-42

Willing EVA, Bentzen P, van Oosterhout C, Hoffmann M, Cable J, Breden F, Weigel D, Dreyer C (2010) Genome-wide single nucleotide polymorphisms reveal population history and adaptive divergence in wild guppies. Mol Ecol 19(5):968-984

Yu X, Bai G, Chen Z, Liu S, Liu J, Warnke SE, Jiang Y (2011) Association of simple sequence repeat (SSR) markers with submergence tolerance in diverse populations of perennial ryegrass. Plant Sci 180:391-398 